\title{
Луконина П.А., Хачемизова Е.Н. \\ Организация учета и анализ расходов по обычной деятельности с применением счетов учета их по элементам и калькуляционным статьям
}

Сочинский государственный университет (Россия, Сочи)

doi:10.18411/lj-31-03-2018-73

idsp: 000001:lj-31-03-2018-73

\section{Аннотация}

Прибыль предприятия напрямую зависит от уровня организации и ведения бухгалтерского и управленческого учета, контроля расходов и их калькулирования по статьям. Это связано с рецессивными тенденциями в российской экономики, уменьшением покупательской активности вследствие падения реальных доходов. Учет затрат на производство и калькулирование себестоимости выпускаемой продукции является важнейшей составляющей бухгалтерского учета организации, поскольку именно он ложится в дальнейшем в основу расчета себестоимости выпускаемой продукции и ее ценообразования. То есть именно благодаря учету затрат и калькулированию рассчитывается такая себестоимость продукции, которая позволит организации получить прибыль в рыночных условиях.

Ключевые слова: расходы, прибыль, учет, калькуляция, расходы по обычной деятельности.

Любая организация, предприятие независимо от сферы своей деятельности первоначально определяет размер прибыли, которую она может получить в результате своего функционирования. Прибыль организации, в свою очередь зависит от стоимости производимой (реализуемой) продукции, а также расходов, которые возникли в рамках ее производства. В общем виде под расходами понимается процесс уменьшения экономических выгод в результате выбытия активов и (или) возникновения обязательств, которые приводят к уменьшению капитала предприятия, за исключением уменьшения вкладов по решению участников (собственников имущества). В России расходы предприятия принято делить на две группы (рис. 1).

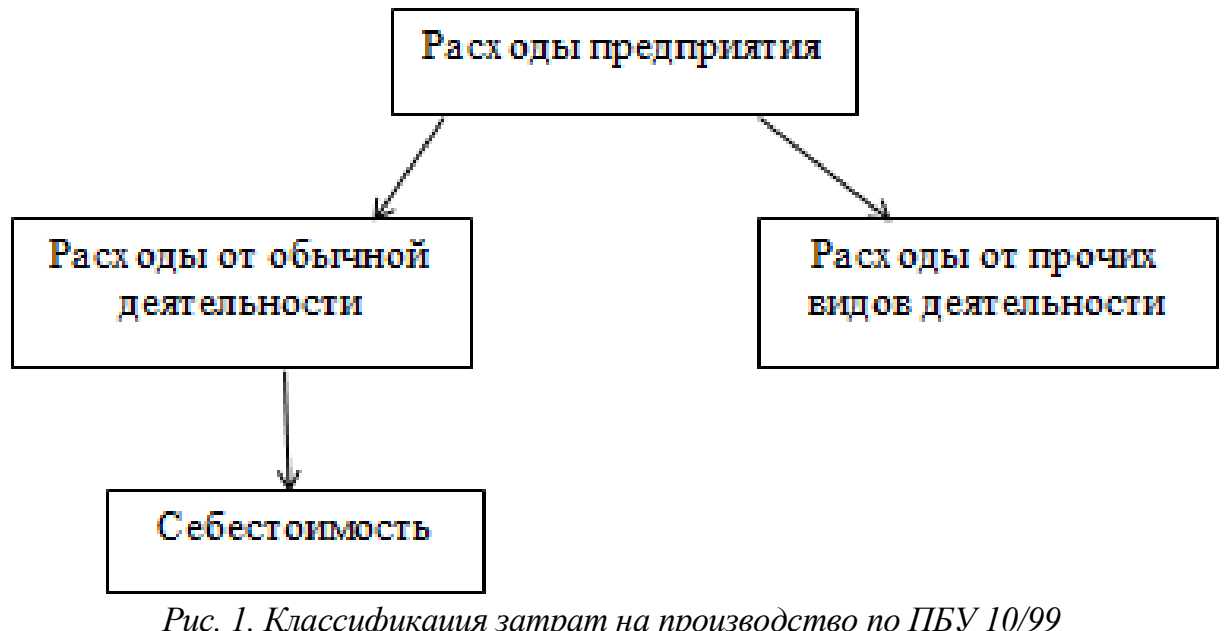

При формировании расходов в рамках группы расходов по обычной деятельности выделяют следующие подгруппы:

- материальные затраты: сырье, материалы, покупные комплектующие изделия и полуфабрикаты, топливо, электроэнергия, теплоэнергия и т. д.;

- затраты на оплату труда;

- затраты на отчисления на социальные нужды; 
- амортизацию;

- прочие затраты (арендная плата, проценты по кредитам банка, налоги и др.).

При этом материальные затраты включают в себя цену всех материалов, сырья, которые приобретаются со стороны для изготовления продукции.

Процесс формирования учета расходов по обычной деятельности можно представить в виде следующей схемы (рис. 2).

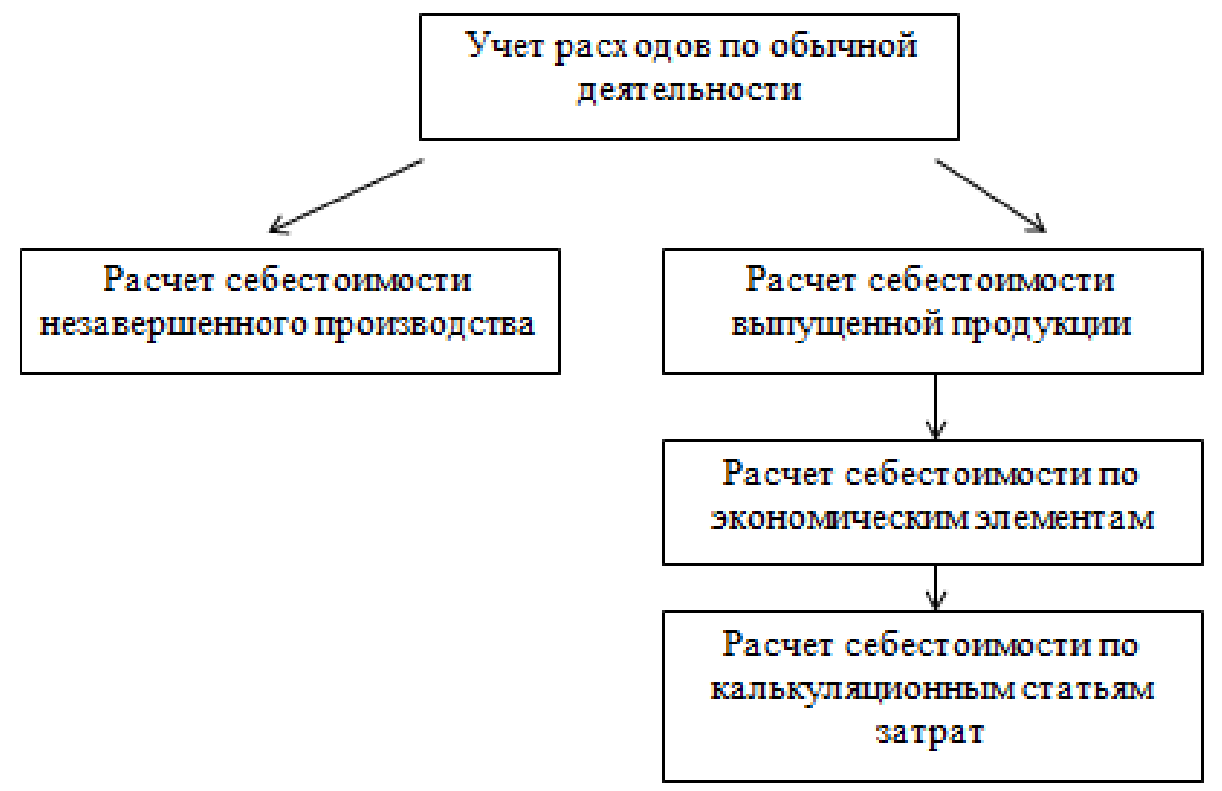

Рис. 2. Формирование учета расходов по обычной деятельности

При организации учета расходов по обычным видам деятельности применяются несколько счетов учета.

Первый счет № 20 «Основное производство». По своей сути по отношению к бухгалтерскому балансу данный счет является активным, а по своему назначению калькуляционный. В экономическом отношении данный счет позволяет сформировать состояние хозяйственных процессов.

Для того чтобы определить себестоимости продукции организациями применяется счет № 23 «Вспомогательные производства».

По своему экономическому назначению данный счет организации соответствует счету № 20 «Основное производство».

Для того чтобы производить учет расходов в текущем отчетном месяце, применяется счет № 97 «Расходы будущих периодов». В данный счет включаются расходы, связанные с освоением новых видов мебельной продукции.

Также при учете материальных затрат на производство продукции в обязательном порядке необходимо иметь определенный финансовый резерв для оплаты предстоящих расходов (например, для выплаты отпускного пособия для сотрудников, которые собираются в отпуск и пр.).

Для того чтобы сформировать данный резерв в организациях применяется форма счета № 96.

Отдельно стоит остановиться на вопросе поддержания работоспособности производства. Данные расходы учитываются на счетах № 25-26.

Счет 25 позволяет отразить реальные расходы цеховСчет 26 позволяет отразить все расходы по управлению предприятиемВажно отметить, что в бухгалтерском балансе данные счета не находят отражения, поскольку не имеют сальдо. 
Так как в любом производстве может быть бракованная продукция, то на предприятии в рамках ведения бухгалтерского учета необходимо осуществлять ее учет. Для этого применяется стандартизированная форма №28 «Брак в производстве».

Также при учете расходов по обычной деятельности осуществляется их учет по калькуляционным статьям.

В рамках группировки расходов по статьям калькуляции они всегда объединяются по направлениям их использования, по месту их возникновения, то есть те расходы, которые формируются в процессе производства продукции, в процессе обслуживания производства, управленческом аспекте и пр. Такой вариант позволяет выявить, сколько было и где израсходовано, на какие цели были направлены средства. Также посредством калькулирования по статьям можно выделить отдельные группы расходов по цехам, иным структурным подразделениям организации.

Расходы, которые формируются по статьям себестоимости, отличаются от расходов по ее элементам тем, что они фактически отражают затраты, которые связаны напрямую с процессом производства продукции и ее реализацией в текущий отчетный период. В то время как затраты по элементам позволяют отразить все расходы организации, в том числе и остатки незавершенного производства, а также расходы будущих периодов.

Таким образом, посредством анализа себестоимости продукции по калькуляционным статьям и по элементам затрат позволяет на практике выявить факторы, которые способствуют как увеличению, так и снижению себестоимости и определяют основные направления увеличения прибыльности производства на основе снижения затрат.

$$
* * *
$$

1. Федеральный закон РФ от 06.12.2011 № 402-Ф3 (ред.

от 23.05.2016) «О бухгалтерском учете». [Электронный ресурс]: Доступ из справ. - правовой системы «Консультант Плюс».

2. Приказ Минфина России от 06.05.1999 № 33н (ред. от 06.04.2015) «Об утверждении Положения по бухгалтерскому учету «Расходы организации» ПБУ 10/99» (Зарегистрировано в Минюсте России 31.05.1999 № 1790). [Электронный ресурс]: Доступ из справ.-правовой системы «Консультант Плюс».

3. Алексеева Г.И. Бухгалтерский учет. - М.: МФПУ Синергия, 2014. - 720 с.

4. Бабаев Ю.А. Теория бухгалтерского учета. - М.: Проспект, 2015. - 240 с.

5. Медведев А.В. Бухгалтерский учет, анализ, аудит: учебное пособие. - М.: Юнити-Дана, 2015. - 558 с.

\section{Марина М.М. \\ Банкротство предприятий и организаций: понятие и сущность}

Новосибирский государственный университет экономики и управления (Россия, Новосибирск)

doi:10.18411/lj-31-03-2018-74

idsp: 000001:lj-31-03-2018-74

\section{Аннотация}

В статье рассматривается сущность банкротства, даются определения понятия банкротства различными авторами и с различных точек зрения.

Ключевые слова: финансовый кризис, несостоятельность, банкротство.

Одним из ключевых вопросов экономики любой страны, является вопрос о банкротстве. Вследствие нестабильности российской экономики, которая сопровождается задержкой платежей, резким сокращением инвестиций, сокращением государственного бюджета увеличилось количество предприятий, которые стали банкротами или находятся в данной стадии. Поэтому в данной ситуации приобретает первостепенное значение прогноз вероятности банкротства, поскольку своевременная диагностика позволит 